Task No.: WSRC-RP-96-62

KEYWORDS:

HYDRAULICS

FLOW RATE

ACCELERATTORS

BLANKET

RETENTION:

PERMANENT

\title{
HYDRAULIC TESTING OF APT \\ BLANKET ASSEMBLIES (U)
}

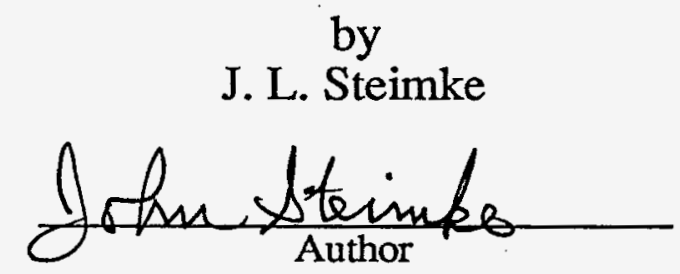

ISSUED: May 1996

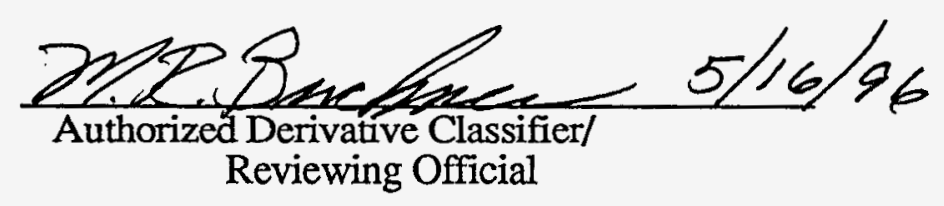

\section{SRTC SAVANNAH RIVER TECHNOLOGY CENTER, AIKEN, SC 29808 \\ Westinghouse Savannah River Company \\ Prepared for the U.S. Department of Energy under \\ Contract DE-AC09-89SR18035}

iii

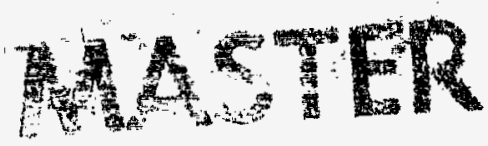




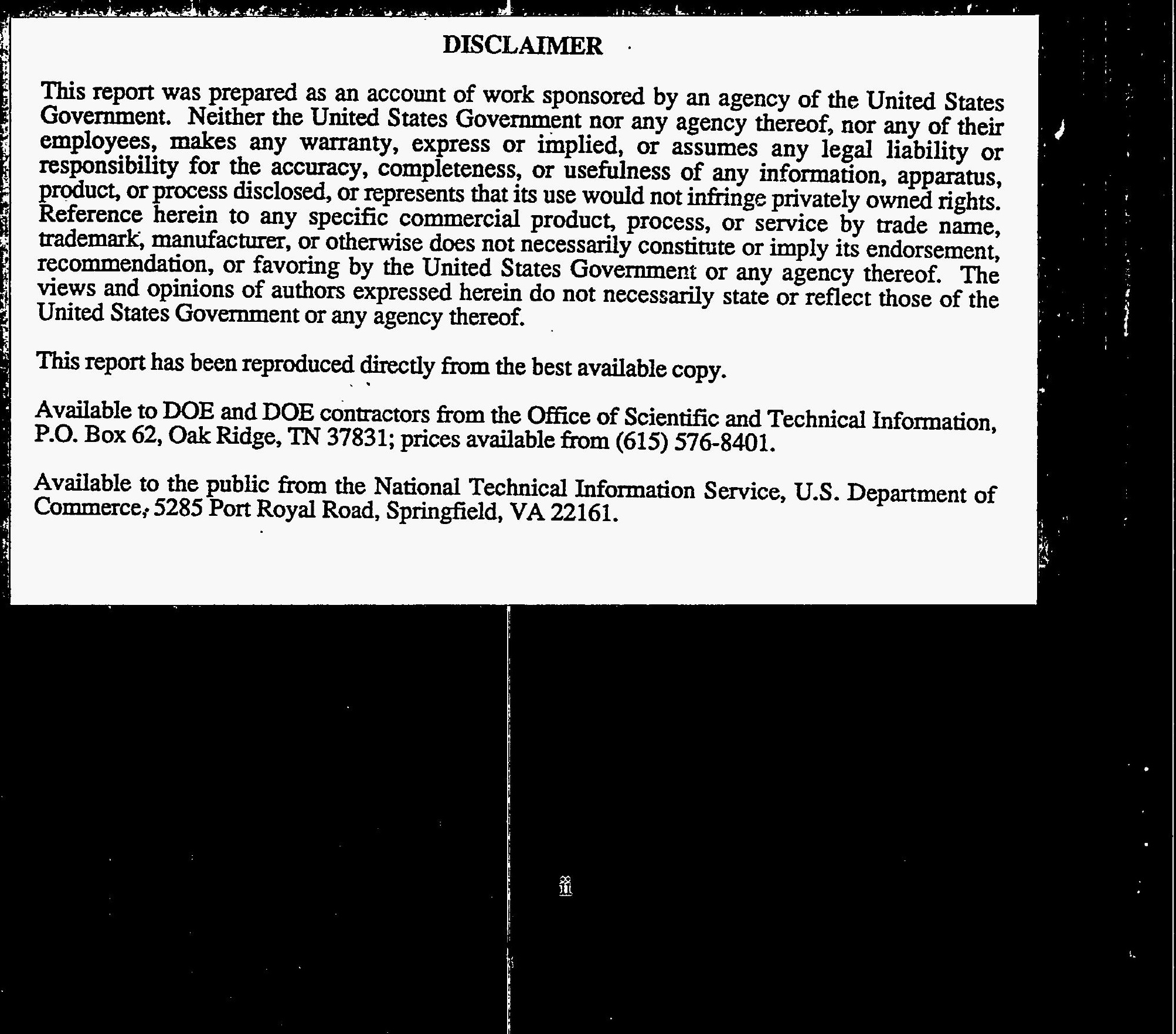




\section{Document: \\ Title: \\ Task: \\ Task Title: \\ WSRC-TR-96:0119 \\ Hydraulic Testing of APT Blanket Assemblies \\ WSRC-RP-96-62 \\ Test Samples for Area-A Tests in LANSCE Accelerator at LANL (U)}

Approvals

Muarle Re Ausica

M. R. Duignan, Technical Reviewer
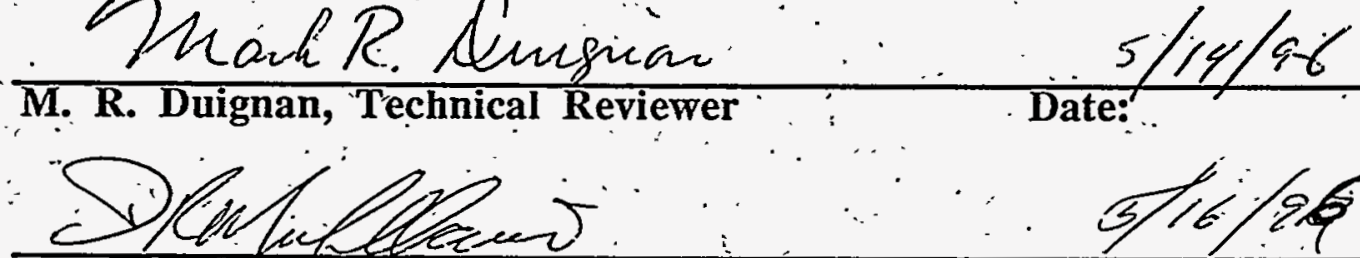

D. R. Muhbbaier; Responsible Manager

Date:

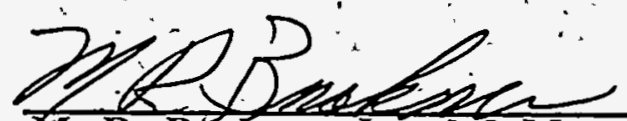

M. R. Buckner, Level 3 Manager Date:

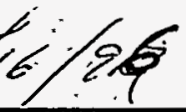




\section{DISCLAIMER}

Portions of this document may be illegible in electronic image products. Images are produced from the best available original document. 


\begin{abstract}
The Thermal Fluids Laboratory (TFL) conducted hydraulic tests on two versions of the test samples of the Low Flux Blanket Assembly and on four High Flux Blanket Assemblies in support of the Area-A Tests to be conducted at Los Alamos National Laboratory (LANL)[1]. The first purpose for the tests was to check for manufacturing flaws that might have constricted cooling passages. No evidence of manufacturing flaws was found. The second purpose was to provide hydraulic information that could be used to calculate orifice sizes for limiting flow to the assemblies after installation. During the TFL hydraulic tests differential pressures were measured for the six pieces of hardware as functions of water flowrate. In all cases differential pressure was proportional to flowrate squared. The particular functional relationships needed by LANL are listed in graphical and tabular form.
\end{abstract}




\section{CONTENTS}

1. INTRODUCTION 1

2. DESCRIPTION OF HARDWARE AND TESTING 1

3. TEST RESULTS 1

4. ACKNOWLEDGMENT 2

5. TABLES 3

6. FIGURES 5

1

1

2

3 


\section{INTRODUCTION}

Accelerator Production of Tritium (APT) had been proposed as a method of producing tritium since the SRS production nuclear reactors are no longer available. An accelerator will produce a beam of energetic protons (hydrogen nuclei). The protons will strike a tungsten target producing neutrons. The neutrons will interact with helium 3 gas in what Los Alamos National Laboratory (LANL) terms the blanket region to produce tritium. LANL asked Savannah River Technology Center (SRTC) to design and perform initial verification testing of six blanket assemblies before they are tested in the LANSCE accelerator facility at LANL.

\section{DESCRIPTION OF HARDWARE AND TESTING}

The High Flux assemblies are documented in drawing EES-22500-R4-010. They have a simple flow path with no branching.

The Mark I Blanket Assembly is documented in the following SRS drawings; EES-22500-R1-001, EES-22500-R3-002 and EES-22500-R3-003. Figure 1 is a simplified drawing of the Mark I Assembly. The Mark I Assembly has two inlet coolant tubes that supply coolant, called herein the common flow, to a common bottom plenum. Most of the coolant, called herein the outer branch flow, flows out of the bottom plenum to cool the eight lead filled tubes. This flow enters a top plenum and exits the assembly through tube at the side of the top plenum. The remainder of the flow, called herein the inner branch flow, cools the helium cylinder and exits the top of the assembly.

The Mark II Blanket Assembly is documented in the following SRS drawings; EES-22500-R1-004, EES-22500-R4-005, EES-22500-R3-006 and EES-22500-R4-009. Figure 2 is a simplified drawing of the Mark II Assembly. The Mark II Assembly also has two inlet coolant tubes that supply the common flow of coolant to a common bottom plenum. Most of the coolant, the outer branch flow, moves out of the bottom plenum, through narrow passages at the outside of the bottom half of the assembly, to a common top plenum for the bottom half of the assembly. A tube connects the top plenum for the bottom half of the assembly to the bottom plenum for the top half of the assembly. The outer branch flow flows through narrow passages at the outside of the top half of the assembly to a common top plenum. The outer branch flow exits the top plenum through a tube at the side of the top plenum. The remainder of the flow, the inner branch flow, moves through orifices and through annuli surrounding four helium cylinders in the bottom half of the assembly. The annulus flows constituting the inner branch flow combine in a central plenum and then divide again to flow through annuli around the four helium cylinders in the top half of the assembly. The four flows combine in a top plenum and the inner branch flow exits the assembly through a tube.

The TFL flow loops are shown in Figure 3. Process water was regulated to 30 psig. The water supply was connected to the test assembly using flexible hose. Valve 3 was a shutoff valve. The actual attachment of the hose to the assembly was made using Swagelok tees. The side arm of the tee was connected to a differential pressure transducer. The discharge side connection was also made with Swagelok tees. Valves were used to set a range of flows, which were measured with calibrated rotameters. The rotameters were read manually and the results recorded in a laboratory notebook. The calibrated differential pressure transducers were read with calibrated multimeters and the results were recorded. Both differential pressure transducers have an uncertainty of \pm 0.1 psid. Rotameter 1 , used for the High Flux Assemblies and the outer branch flow of the Mark I and Mark II Assemblies, has an uncertainty of \pm 0.04 gpm. Rotameter 2, used only for the inner branch flow of the Mark I and Mark II Assemblies, has an uncertainty of $\pm 0.06 \mathrm{gpm}$.

\section{TEST RESULTS}

Table 1 lists flows and differential pressures for the four High Flux Assemblies. Figure 4 is a plot of flow squared vs. differential pressure. The flow vs. pressure relationship is 
essentially the same for the four High Flux Assemblies. Combining data for all four assemblies the relationship is

$$
\Delta \mathrm{P}_{\mathrm{hf}}=0.278 \mathrm{~F}^{2}
$$

where $\Delta \mathrm{P}_{\mathrm{hf}}$ has units of psid and $\mathrm{F}$ has units of gpm. The leading constant was fit in the least squares sense.

Tables 2 and 3 list flows and differential pressures for the Mark I and Mark II Assemblies, respectively. The first four columns are directly measured flows and pressures. Note that at least one of the flows is always zero. The fifth column is the inferred differential pressure from the inlet to the branch point, the common flow path, and is equal to the differential pressure attached to the outlet branch that carries no flow. There is no pressure difference in the branch with no flow. The inferred differential pressure in the outer branch is equal to the measured differential pressure from the inlet to the outer branch outlet minus the inferred differential pressure for the common flow path. The inferred differential pressure in the inner branch is equal to the measured differential pressure from the inlet to the inner branch outlet minus the inferred differential pressure for the common flow path. Figure 5 and 6 are plots of the differential pressures vs. flow squared. The relationships between differential pressure and flow squared are listed below. The leading constants were fit in the least squares sense.

$\begin{array}{lll}\text { Common path } & \frac{\text { MarkI }}{\Delta \mathrm{P}_{\mathrm{cp}}=0.0560\left(\mathrm{~F}_{\mathrm{ob}}+\mathrm{F}_{\mathrm{ib}}\right)^{2}} & \frac{\text { Mark II }}{\Delta \mathrm{P}_{\mathrm{cp}}=0.0262\left(\mathrm{~F}_{\mathrm{ob}}+\mathrm{F}_{\mathrm{bb}}\right)^{2}} \\ \text { Outer branch } & \Delta \mathrm{P}_{\mathrm{ob}}=0.1599 \mathrm{~F}_{\mathrm{ob}}{ }^{2} & \Delta \mathrm{P}_{\mathrm{ob}}=0.2383 \mathrm{~F}_{\mathrm{ob}}{ }^{2} \\ \text { Inner branch } & \Delta \mathrm{P}_{\mathrm{ib}}=0.892 \mathrm{~F}_{\mathrm{ib}}{ }^{2} & \Delta \mathrm{P}_{\mathrm{ib}}=0.322 \mathrm{~F}_{\mathrm{ib}}{ }^{2}\end{array}$

\section{ACKNOWLEDGMENT}

Jimmy Mills performed all of the tests and instrument calibrations. 


\section{Table 1}

\section{Hydraulic Test Data for High Flux Assemblies}

$\begin{array}{llllll}\begin{array}{l}\text { Assembly } \\ \text { number }\end{array} & \begin{array}{l}\text { Flow } \\ \text { gpm }\end{array} & \begin{array}{l}\text { Differential } \\ \text { Pressure } \\ \text { psid }\end{array} & \begin{array}{l}\text { Assembly } \\ \text { number }\end{array} & \begin{array}{l}\text { Flow } \\ \text { gpm }\end{array} & \begin{array}{l}\text { Differential } \\ \text { Pressure } \\ \text { psid }\end{array} \\ 1 & & & & & \\ 1 & 0.70 & 0.25 & 3 & 0.70 & 0.25 \\ 1 & 1.54 & 0.88 & 3 & 1.54 & 0.82 \\ 1 & 2.54 & 2.01 & 3 & 2.54 & 2.01 \\ 1 & 3.69 & 3.81 & 3 & 3.69 & 3.77 \\ 1 & 4.66 & 6.04 & 3 & 4.66 & 5.91 \\ 1 & 4.66 & 6.04 & 3 & 4.66 & 5.91 \\ 1 & 3.69 & 3.77 & 3 & 3.69 & 3.77 \\ 1 & 2.54 & 2.04 & 3 & 2.54 & 1.95 \\ 1 & 1.54 & 0.88 & 3 & 1.54 & 0.79 \\ 1 & 0.70 & 0.25 & 3 & 0.70 & 0.25 \\ 2 & 0.00 & 0.00 & 3 & 0.00 & 0.00 \\ 2 & 0.70 & 0.28 & 4 & 0.70 & 0.25 \\ 2 & 1.54 & 0.88 & 4 & 1.54 & 0.88 \\ 2 & 2.54 & 1.95 & 4 & 2.54 & 1.98 \\ 2 & 3.69 & 3.81 & 4 & 3.69 & 3.87 \\ 2 & 4.66 & 5.88 & 4 & 4.66 & 5.94 \\ 2 & 4.66 & 5.88 & 4 & 4.66 & 5.94 \\ 2 & 3.69 & 3.84 & 4 & 3.69 & 3.90 \\ 2 & 2.54 & 1.98 & 4 & 2.54 & 1.98 \\ 2 & 1.54 & 0.88 & 4 & 1.54 & 0.88 \\ 2 & 0.70 & 0.25 & 4 & 0.70 & 0.25 \\ & 0.00 & 0.00 & 4 & 0.00 & 0.00\end{array}$




\section{Table 2 \\ Hydraulic Test Data for Mark I Assembly}

\begin{tabular}{|c|c|c|c|c|c|c|}
\hline $\begin{array}{l}\text { flow to- } \\
\text { outer } \\
\text { branch, } \\
\text { gpm }\end{array}$ & $\begin{array}{l}\text { flow to } \\
\text { inner } \\
\text { branch, } \\
\text { gpm }\end{array}$ & $\begin{array}{l}\text { differential } \\
\text { pressure } 1 \\
\text { psid }\end{array}$ & $\begin{array}{l}\text { differential } \\
\text { pressure } 2 \\
\text { psid }: \\
\end{array}$ & $\begin{array}{l}\text { inferred } \\
\text { diff. pres. } \\
\text { in common } \\
\text { path, } \\
\text { psid }\end{array}$ & $\begin{array}{l}\text { inferred } \\
\text { diff. pres. } \\
\text { in outer } \\
\text { branch, } \\
\text { psid }\end{array}$ & $\begin{array}{l}\text { inferred } \\
\text { diff. pres } \\
\text { in inner } \\
\text { branch, } \\
\text { psid } \\
\because\end{array}$ \\
\hline 00 & 0.00 & 0.02 & 0.01 & 0.01 & 0.00 & -0.00 \\
\hline .70 & 0.00 . & 0.17 & 0.08 & 0.08 & 0.10 & -0.00 \\
\hline 1.54 & 0.00 & $=0.61$ & 0.23 & 0.23 & 0.38 & 0.00 \\
\hline 2.54 & 0.00 & 1.53 & 0.45 & $0.4 \widehat{5}$ & 1.07 & 0.00 \\
\hline 3.69 & 0.00 & 2.97 & 0.80 & 0.80 & 2.17 & -0.00 \\
\hline 5.00 & 0.00 & 5.36 & 1.40 & 1.40 & $3.96^{\circ}$ & -0.00 \\
\hline 14 & 0.00 & 5.64 & 1.43 & 1.43 & 4.22 & 0.00 \\
\hline 00 & 0.48 & 0.02 & 0.36 & 0.02 & -0.00 & 0.34 \\
\hline .00 & 0.97 & 0.05 & 1.02 & 0.05 & 0.00 & 0.97 \\
\hline 00 & 1.45 & 0.14 & 2.18 & $0.14^{\circ}$ & -0.00 & 2.04 \\
\hline 00 & 1.93 & 0.24 & 3.44 & 0.24 & -0.00 & $3: 20$ \\
\hline
\end{tabular}

\section{Táble 3}

\section{Hydraulic Test Data for Mark II Assembly}

flow to flow to differential differential inferred inferred inferred outer inner "pressure 1 pressure 2 diff. pres. diff. pres. diff. pres. branch, $\because$ branch, psid . $:$ psid $\quad$ in common in outer in inner gpm $\quad$ gpm.. path, ". branch, branch, psid psid psid

$\begin{array}{lllllll}5.14 & 0.00 & 6.89 & 0.66 & 0.66 & 6.23 & 0.00 \\ 3.69 & 0.00 & 3.68 & 0.38 & 0.38 & 3.30 & 0.00 \\ 2.54 & 0.00 & 1.86 & 0.22 & 0.22 & 1.64 & 0.00 \\ 1.54 & 0.00 & 0.82 & 0.12 & 0.12 & 0.69 & 0.00 \\ 0.70 & 0.00 & 0.25 & 0.06 & 0.06 & 0.19 & 0.00 \\ 0.00 & 0.00 & 0.00 & 0.03 & 0.00 & 0.00 & 0.03 \\ 0.00 & 2.22 & 0.16 & 1.73 & 0.16 & 0.00 & 1.57 \\ 0.00 & 1.45 & 0.06 & 0.75 & 0.06 & 0.00 & 0.69 \\ 0.00 & 0.97 & 0.03 & 0.41 & 0.03 & -0.00 & 0.37 \\ 0.00 & 0.48 & 0.03 & 0.1 .6 & 0.03 & -0.00 & 0.12\end{array}$


Figure 1

Elevation of Mark I Assembly

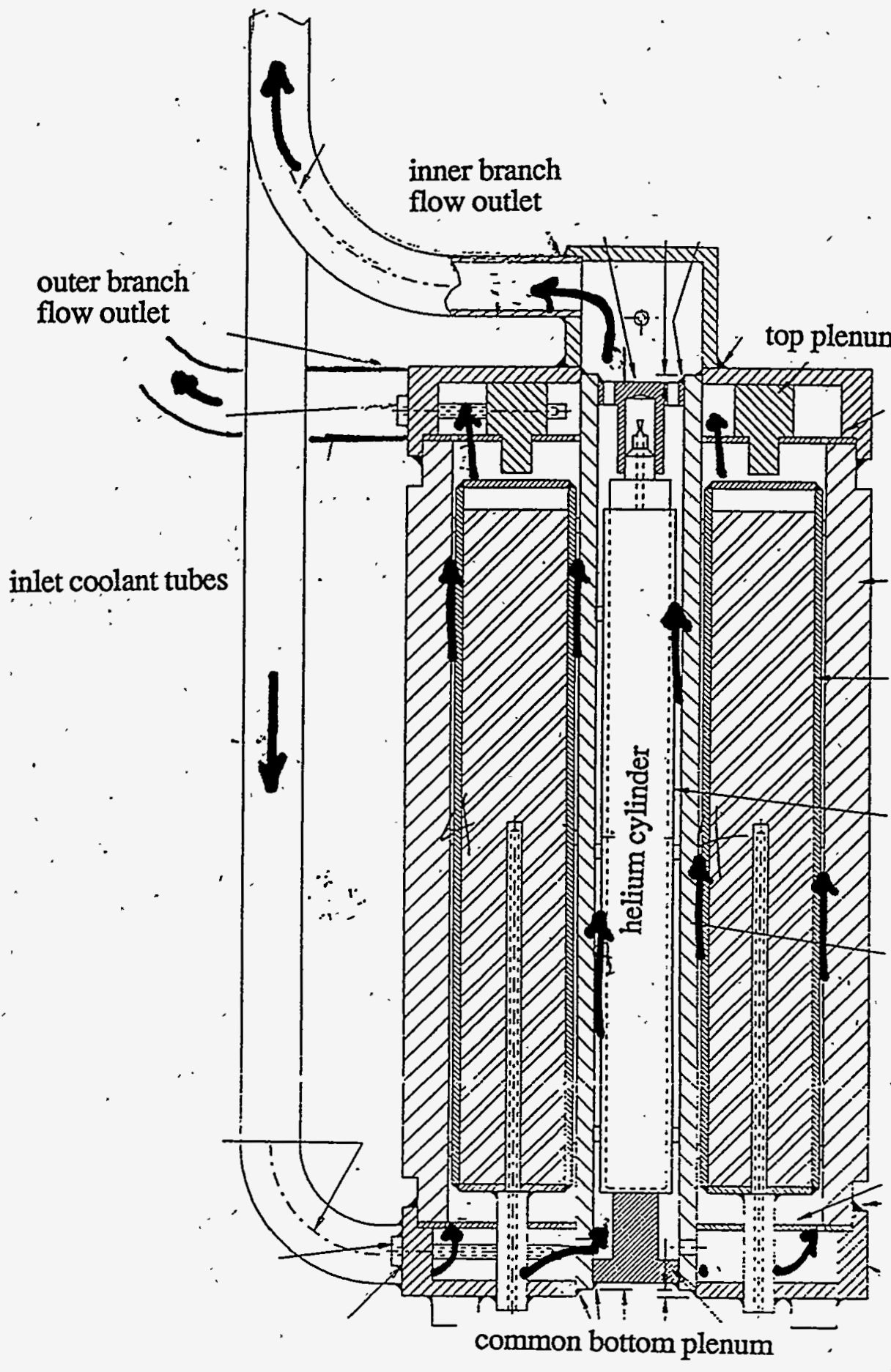

lead filled tube 
Figure 2

Elevation of Mark II Assembly

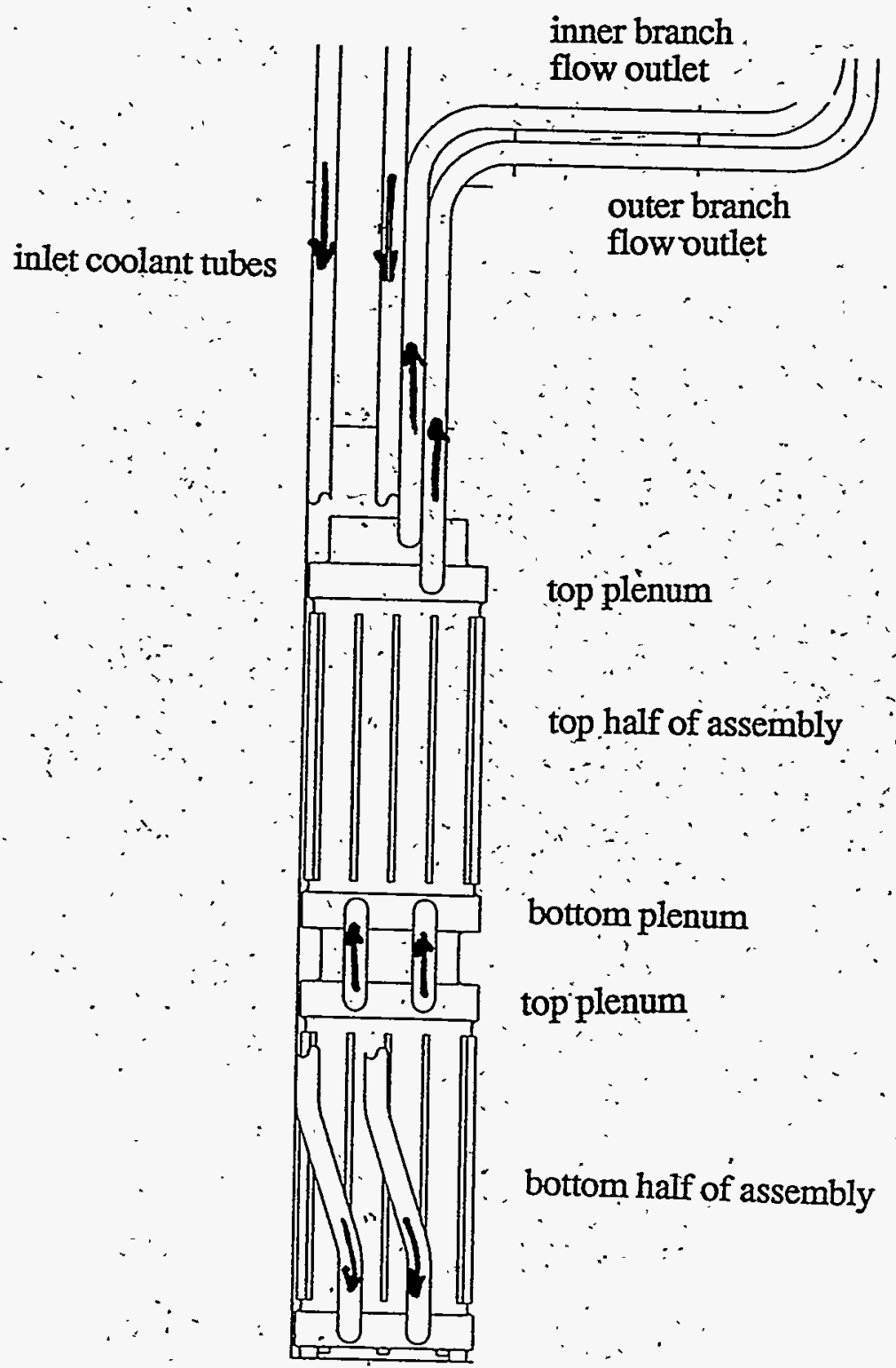

bottom plenum 


\section{Figure 3 \\ Test Loops for APT Assemblies}

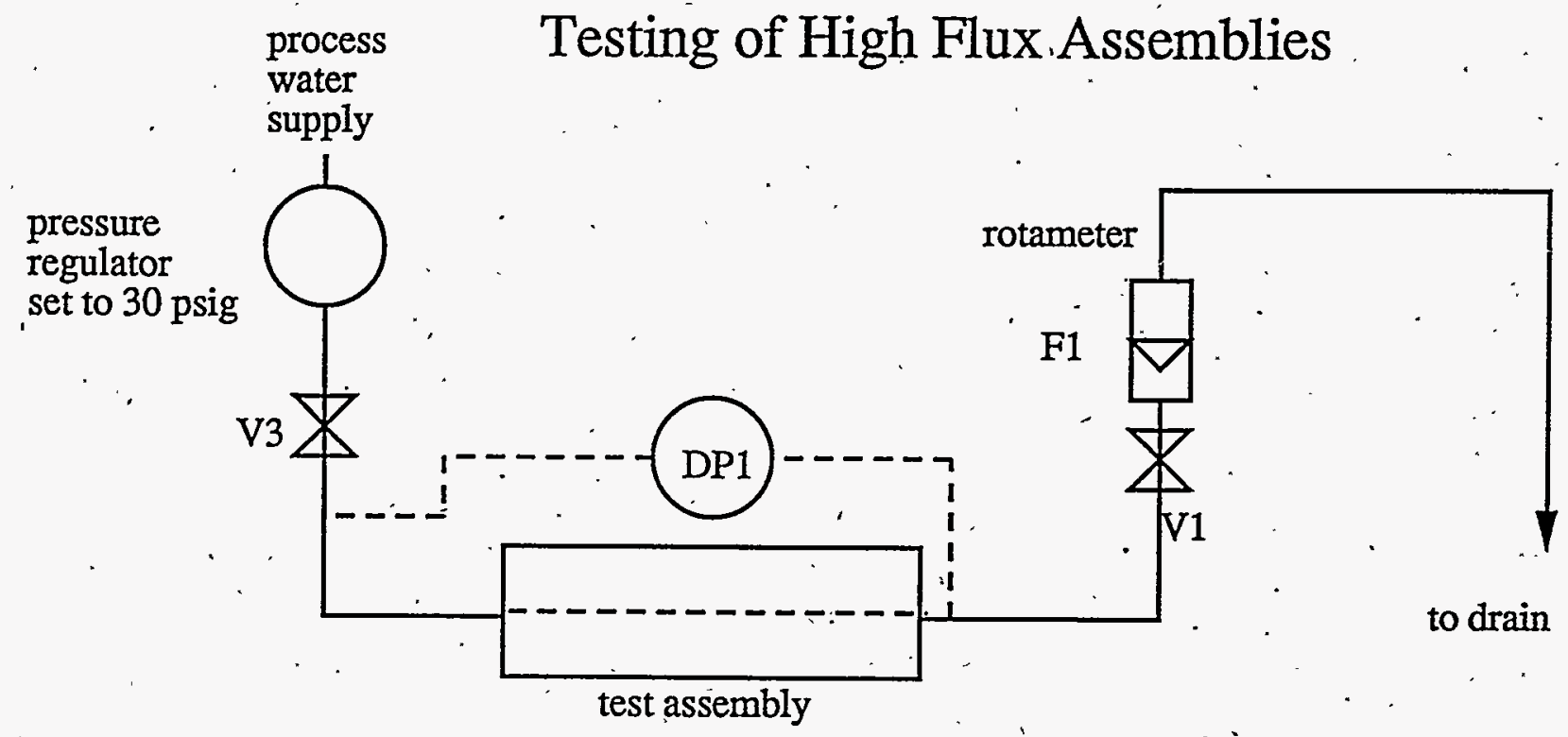

\section{Testing of Mark I and Mark II Assemblies}

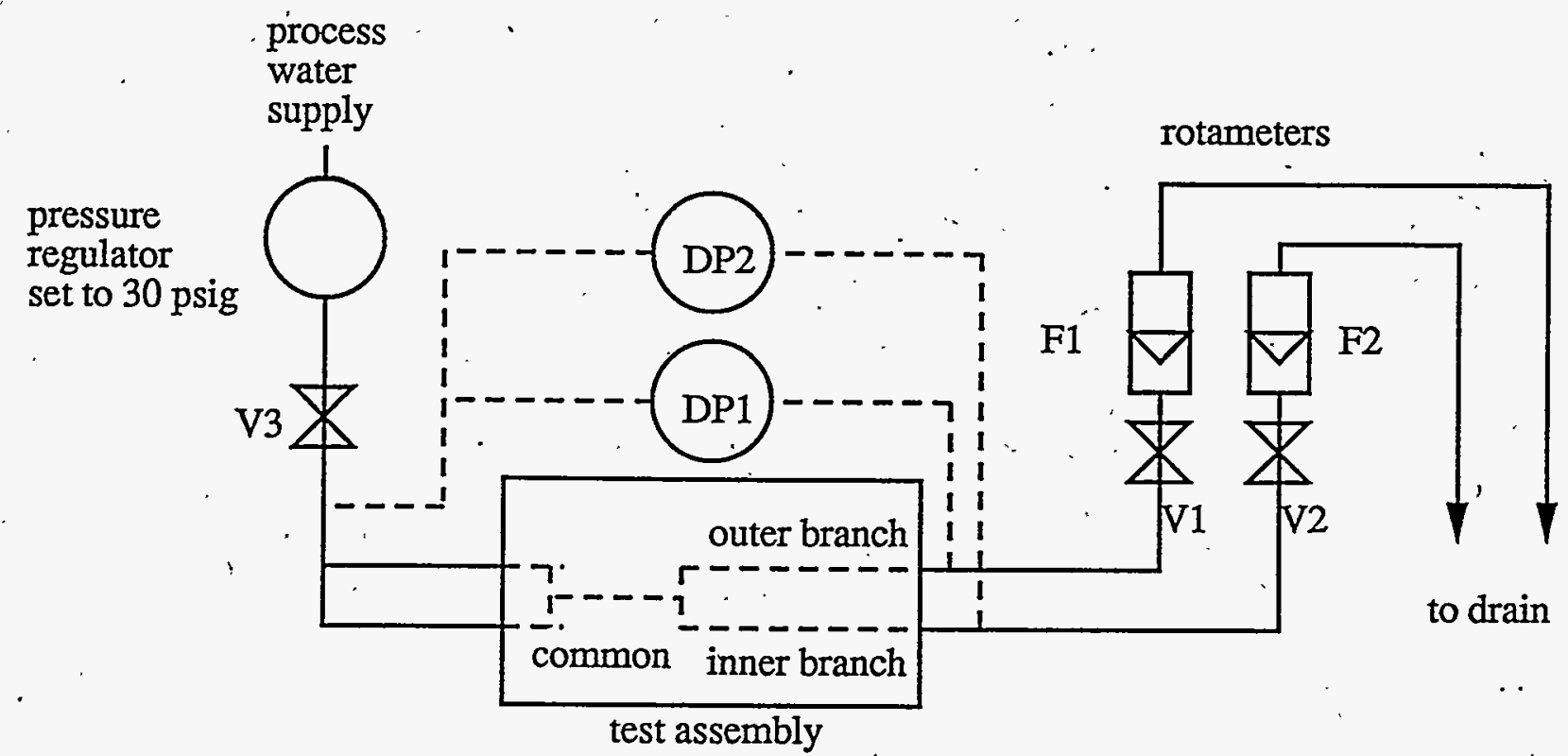


Figure 4 .

Hydraulic:Test Data for High Flux Assemblies,

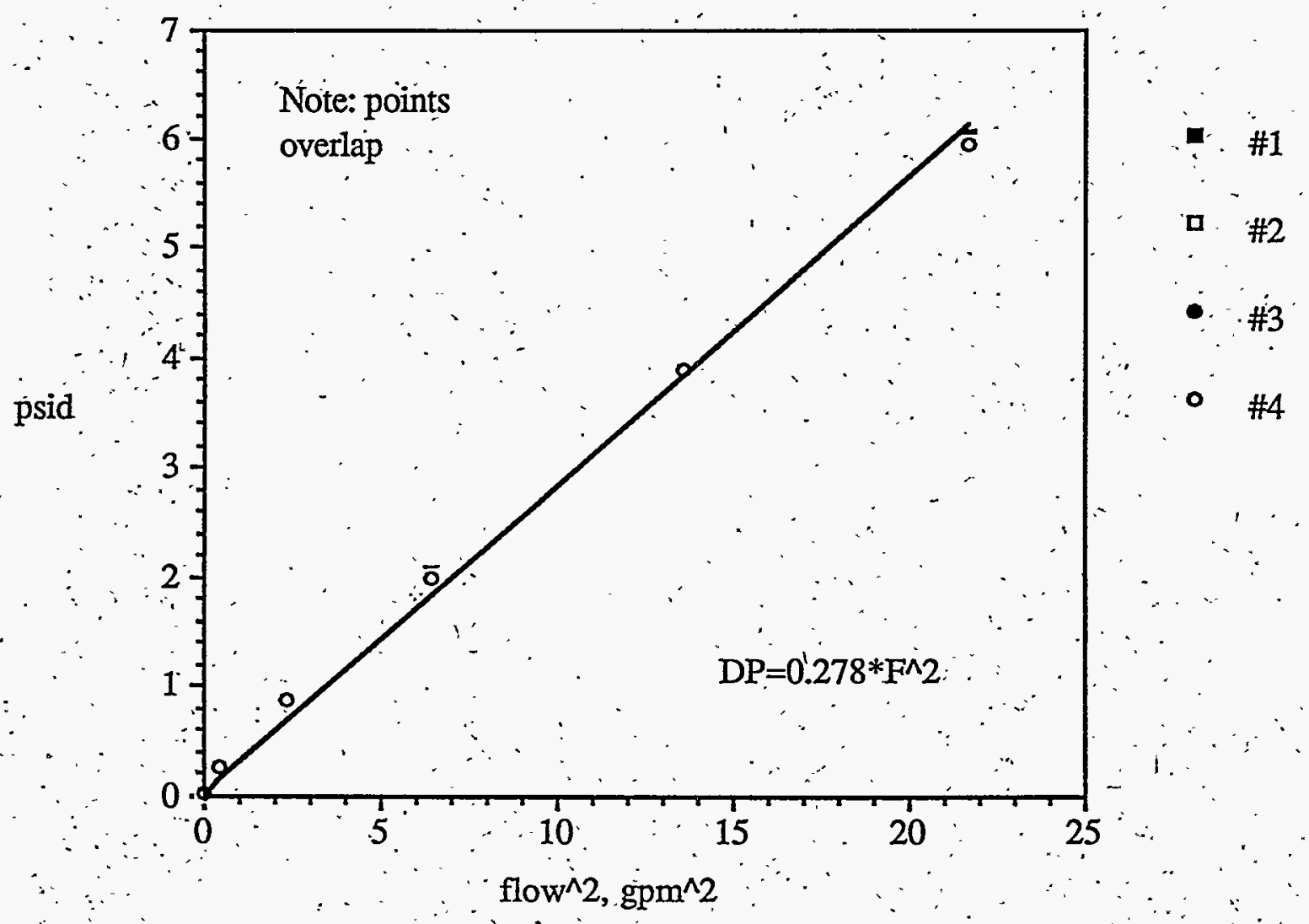


Figure 5 Hydraulic Test Data for Mark I Assembly

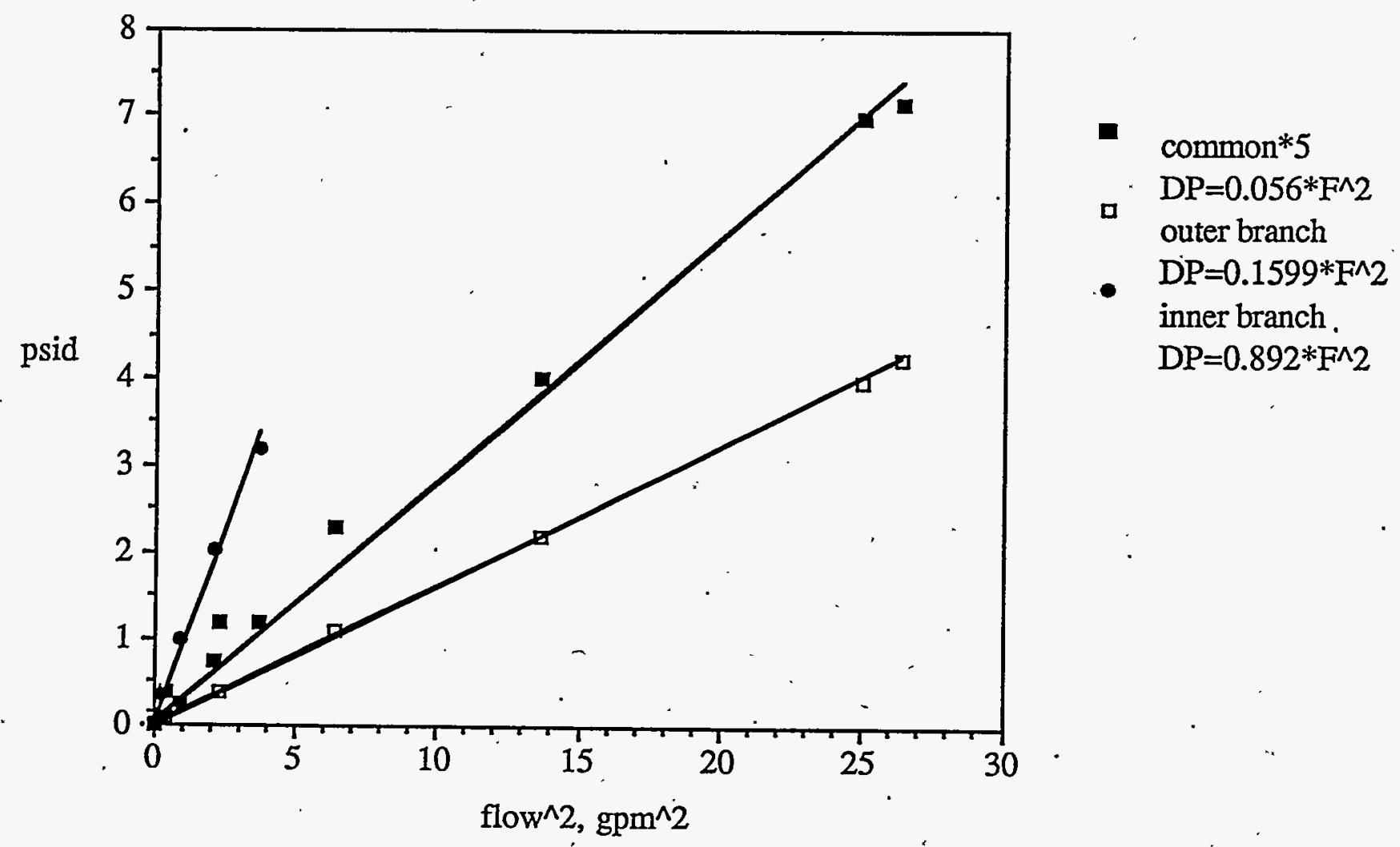

Figure 6 Hydraulic Test Data for Mark II Assembly

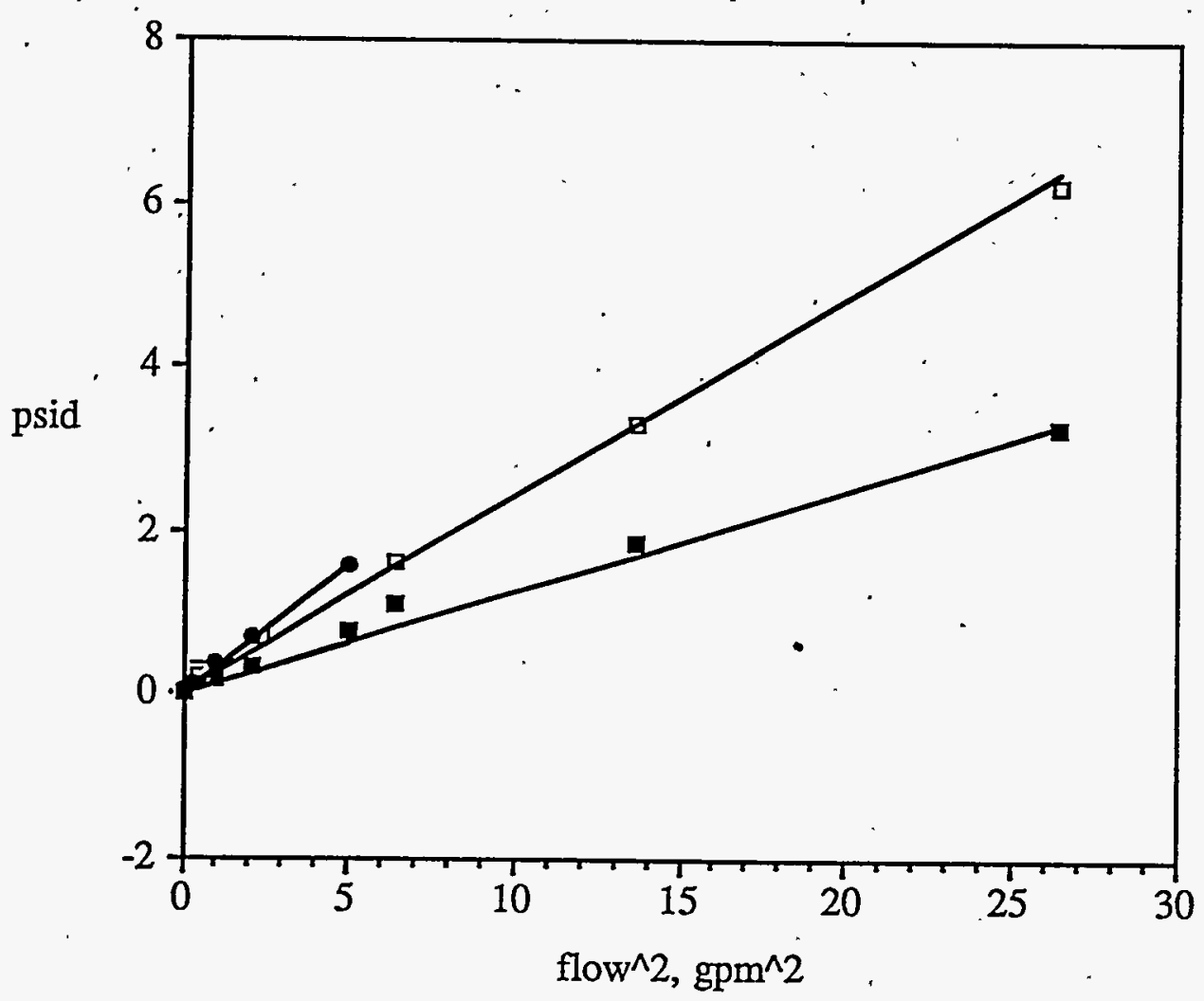

common*5

$\mathrm{DP}=0.0262 * \mathrm{~F} \wedge 2$ outer branch $\mathrm{DP}=0.2383 * \mathrm{~F}^{\wedge} 2$ inner branch $\mathrm{DP}=0.322 * \mathrm{~F}^{\wedge} 2$ 